\title{
A Survey on Video Watermarking Technologies based on Copyright Protection and Authentication
}

\author{
Hedayath Basha Shaik \\ Assistant Professor, ECE Dept. \\ R.M.K. College of Engineering \\ and Technology \\ Chennai, India
}

\author{
Gangatharan. N \\ Professor and Head of the \\ Department ECE \\ R.M.K. College of Engineering \\ and Technology \\ Chennai, India
}

\author{
Tamilchelvan. R \\ CEO \\ Vidhara Secure Com Company \\ Chennai, India
}

\begin{abstract}
Digital Watermark is class of marker or symbol secretly embedded in a multimedia signal such as Audio, Image or Video. It is used to identify the ownership of the multimedia signal. Video watermarking is an emerging area for various applications like copy control broadcast monitoring, video authentication, copyright protection and enhanced video coding. The main objective of this paper is to present survey and comparisons of various available techniques on video watermarking based on copyright protection and identification. Comparative study of various technologies gives the significant information about the PSNR, payload, quality factor and also the various attacks used in video watermarking techniques. The best techniques in various scenarios are discussed in this paper which will help the research scholars in field of video watermarking.
\end{abstract}

Keywords: authentication; copyright protection; video attacks; psnr; payload.

\section{INTRODUCTION}

Broadly the digital data is managed using the digital rights management (DRM) technologies where the DRM systems possess the following techniques they are a) encryption b) digital Certificates c) watermarking d) access control e) secure communication protocols f) fingerprinting g) rights specification language $\mathrm{h}$ ) trust infrastructure and i) hashing. So the watermarking technique is one of the subset of DRM techniques.

Due to the enormous growth of digital multimedia technologies the use of digital signals incredibly increases, so the attention to the field of digital authentication is increasing. Digital watermarking is documented as an efficient measure for copyright protection of digital multimedia signals. The digital watermarking is classified in terms of three categories they are a) spatial domain watermarking b) frequency domain watermarking and c) feature domain watermarking. In spatial domain watermarking techniques the watermarking is done directly modifying the pixel values of the host multimedia signal. One of the simplest techniques is least significant bit (LSB) modification, where the human visual system (HVS) cannot be able to detect the changes in the original host signal. In transform domain the spatial domain host multimedia signal is transformed into frequency domain using discrete cosine transform (DCT), discrete wavelet transform (DWT) and other available transforms as required by the user. The watermarking is done on the transformed signal where the HVS cannot be able to detect the watermark and it will be completely invisible. In feature domain the watermarking is done on any one of the features of the host multimedia signal. The host multimedia feature is chosen by the user to embed the watermark where the features or entire host signal will be processed by filters like high pass filters. By selecting the edges of the host signal or the feature the embedding process will be carried out for the better authentication and copyright protection.

\section{WATERMARKING SYSTEM}

Audio, image and video watermarking methods uses the exclusive generic building blocks, they are a) watermark embedding system and b) watermark recovery system. The below figure. 1 and figure. 2 shows the watermarking embedding and recovery systems.

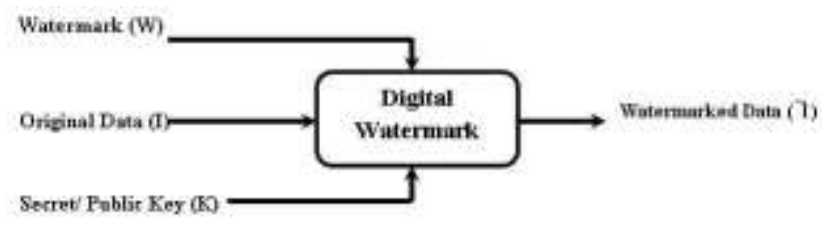

Figure 1 Generic digital watermarking system

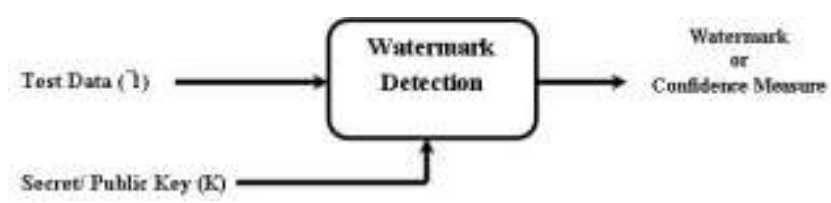

Figure 2 Generic digital watermark recovery system

Here, ' $W$ ' is the watermark used to embed in the original data (I), ' $\mathrm{K}$ ' is the public or private key defined by the user and $\tilde{I}$ is the watermarked data.

Table 1 shows the information regarding different multimedia signals, watermarking types and three different domains. In which frequency domain is mostly used where the user can able to meet certain required criterions.

Table 2 gives the information about various watermarking applications and the various requirements for the user. There is a tradeoff between the robustness, capacity and imperceptibility which is shown in the below figure 3 . The watermarked data may likely to undergo either intentional or 
unintentional modifications two groups of distortion can be distinguished. The first one contains distortions which can be considered as additive noise to the data whereas the distortion in the second group are due to modifications of the spatial or temporal data geometry with the intent to introduce a mismatch between the watermark and the key used for embedding.

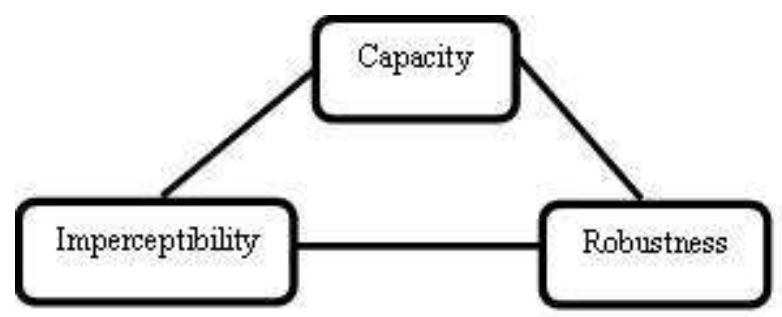

Figure 3 Tradeoff triangle in watermarking system

In the video watermarking process after watermark embedding the watermarked video is send through the channel where the video can under go various attacks.

The watermarked data may likely to undergo either intentional or unintentional modifications two groups of distortion can be distinguished. The first one contains distortions which can be considered as additive noise to the data whereas the distortion in the second group are due to modifications of the spatial or temporal data geometry with the intent to introduce a mismatch between the watermark and the key used for embedding [2]

Table 1. Watermarking domains and types

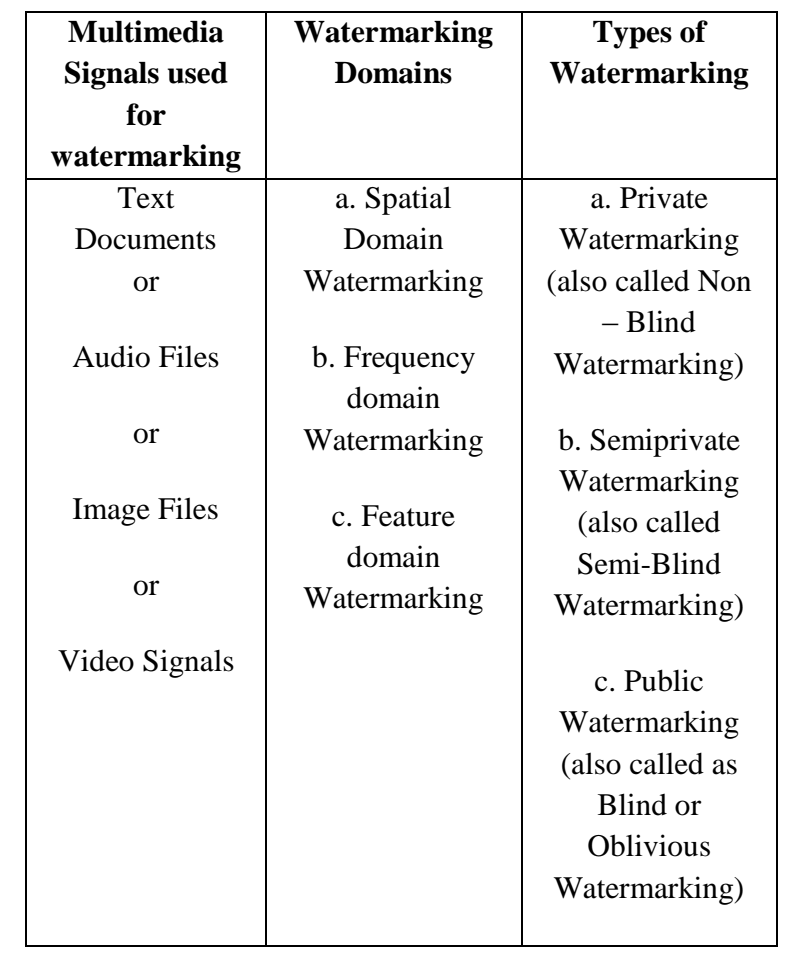

Table 2. Watermarking applications and requirement

\begin{tabular}{|c|c|}
\hline $\begin{array}{c}\text { Watermarking } \\
\text { Applications }\end{array}$ & $\begin{array}{l}\text { Watermarking } \\
\text { Requirements }\end{array}$ \\
\hline
\end{tabular}

\begin{tabular}{|c|l|}
\hline $\begin{array}{c}\text { Watermarking for } \\
\text { Copyright Protection }\end{array}$ & $\begin{array}{l}\text { Recovery with or without the } \\
\text { original data. }\end{array}$ \\
$\begin{array}{c}\text { Fingerprinting for } \\
\text { Traitor Tracking } \\
\text { Extraction or Verification of a } \\
\text { given watermark }\end{array}$ \\
$\begin{array}{c}\text { Watermarking for Copy } \\
\text { Protection }\end{array}$ & Robustness \\
$\begin{array}{c}\text { Watermarking for } \\
\text { Image and Video } \\
\text { Authentication }\end{array}$ & $\begin{array}{l}\text { Imperceptibility } \\
\text { keys }\end{array}$ \\
\hline
\end{tabular}

\section{VIDEO WATERMARKING SYSTEMS}

Video is referred as moving still images or moving frames, video watermarking is done by watermarking each still image using the image watermarking algorithms. It is obviously known that video data is massive in size, for an example if a digital video where each frame is of $720 \mathrm{X} 480$ pixels with color data i.e. ( 24 bits per pixel) then 30 frames/ second has a rate of 248 Mbps. Due to the high rate extension of image watermarking techniques and architectures may be inefficient to handle video watermarking. This is one of the reason by which researchers got motivated to design low complex and efficient hardware implementation [3].

Digital video can be copied frequently exclusive of quality loss. Thereby copyright protection of video is one of the significant issues in digital video transmitting networks than it was with analog TV broadcast. Frank Hartung and Bernd Girod proposed robust watermarking of MPEG 2 encoded video. This scheme is possessing lower complexity comparing with decoding process with watermarking and re-encoding. In this scheme ' $\mathrm{C}$ ' Programming is used to take input and the DCT is applied to the parts of bit stream which contains DC and $\mathrm{AC}$ coefficients and are replaced by $\mathrm{DC}$ and $\mathrm{AC}$ coefficients with watermark. This method is very robust against un-attempted and attempted attacks. It can be applied to MPEG -1, ITU - T H.261 or ITU - T H.263 video coding schemes; the embedded watermark is robust against linear and nonlinear operations like cropping, filtering and quantization in pixel or frequency domain [4].

Chiou - Ting Hsu and Ja - Ling Wu proposes DCT based watermarking for video to hide covert information into signals to protect the authentication and copyright of the digital MPEG videos. Here the watermark is embedded in intra and non-intra frame with dissimilar residual masks. This method is robust to cropping operation and MPEG compression [5]. Frank Hartung and Bernd Girod propose additive spread spectrum methods for embedding watermarks into uncompressed video and compressed MPEG2 video. It is important practically to work on encoded rather than unencoded video. Here the watermark is embedded in entropy coded DCT coefficients [6].

Mitchell D. Swanson et. al. presented a video watermarking method to enable copyright protection into a digital video in which it is based on multi resolution scene based and video dependent watermarking. This method provides imperceptible watermarking and there are two pseudorandom keys used. The watermarking procedure is very robust to several distortions and degradation [7].

Tae - Yun Chung et. al., proposes video watermarking technique by extending the direct spread spectrum on MPEG2 
video. In their proposed technique they increases the video perception quality of the embedded watermarked video by controlling the parameters like strength and area of embedding with respect to the characteristics of the video. The average PSNR value for the three different experimental videos is $29.5 \mathrm{~dB}$ for $4 \mathrm{Mbps}$, $30.6 \mathrm{~dB}$ for $5 \mathrm{Mbps}$, $31.6 \mathrm{~dB}$ for $6 \mathrm{Mbps}$ and $32.1 \mathrm{~dB}$ for $7 \mathrm{Mbps}$, the watermark detection rate is above $97 \%$ for every bit rated MPEG2 video signal [8].

Christoph Busch et. al., proposes modified Koch - Zhao algorithm for video watermarking and observing video streams in a TV broadcasting environment which survives attacks like MPEG2 video compression. The algorithm is well suited for digital video watermarking video streams such as sporting events or movies [9].

Wenwu Zhu et. al., presents a unique approach for Images and video watermarking, their approach is based on $2 \mathrm{D}$ and $3 \mathrm{D}$ DWT. For images SPIHT algorithm is used for compression and the PSNR values between watermarked and original is about $42.77 \mathrm{~dB}$. In concerned with video the watermark is embedded in Group of Pictures (GOP) 16 frames of QCIF foreman sequence 3D wavelet based SPIHT video coder is used for compressing video, the PSNR of original and watermarked frames is $29.99 \mathrm{~dB}$ and $29.46 \mathrm{~dB}$ [10].

Gerhard C. Langelaar et. al., gives a overview of digital and video data watermarking, concerned with video data DCT transform with pseudo random noise is discussed and it is stated that the "Robustness of a watermark is improved by improving the energy of the watermark" also stated that "In the real time environment computational complexity and robustness play very significant role" [11].

Xiamu Niu et. al., team projected a multi-resolution watermarking technique where a gray scale image is embedded into a digital video, 2D and 3D of the video signals are used for embedding watermark. The Hamming code, 2D and 3D Discrete Wavelet Transform (DWT) is used for the signal processing. This watermark is robust against attacks like lossy compression, averaging and frame dropping [12].

T. Brandao et. al., team proposes an analysis on the effects of signal mixture techniques in video watermark detection. Spread spectrum video watermarking is used and various common error correction codes such as $\mathrm{BCH}$, Reed Solomon, with multilevel signaling, Binary Convolution Codes (BCC) with Viterbi decoding is done to improve results [13].

Emmanuel Garcia et. al., introduced a novel framework on texture based watermarking of $3 \mathrm{D}$ video objects. To main objective is to obtain the information hidden in the texture image without degrading the visual perception. Here blind watermarking is proposed using EUREMARK algorithm [14]. Shih - Wel Sun and Pao - Chi Chang presents a new approach based on temporal synchronization. Video watermarking is done through matching the profile statistics. It is given that by position mean and variance in the $\mathrm{X}$ and $\mathrm{Y}$ directions of the frame is send to the receiver to check the received data. The accuracy of frame detection is from $72.41 \%$ to $98.15 \%$ [15].

Gwenael Doerr and Jean - Luc Dugelay done four approaches in the video watermarking based on spread spectrum (SS) technique. a) Every frame is embedded with different watermark with embedding strength parameter ' $\alpha$ ', and secret key ' $\mathrm{K}$ '. (Uncorrelated watermark embedding) (SS system), $\mathrm{Wt}(\mathrm{K})$ is the inserted watermark has normal distribution with zero mean and unit varience.

b) Only one watermark is used to embed into the video frames (Redundant watermark embedding) (SS-1 System)

c) Embedding different watermarks randomly in the video frames (SS-N)

d) SS- $\alpha$

Previous works have mainly focused on robustness i.e. resilience against non-malicious attacks. For example, for applications such as broadcast monitoring, video authentication or data hiding, the watermark has to undergo some signal processing e.g. noise addition, filtering, lossy compression. However, for fingerprinting or copy-control applications, the embedded watermark has also to survive in a hostile environment with malicious users. In this context, security issues have to be addressed [16].

Eugene T. Lin et. al., developed a state machine key generator which help the user to detect the watermark even if synchronization of the video signal is lost. This blind watermarking technology is used to establish and maintain temporal synchronization. It is very resilient against temporal synchronization attacks [17].

Mauro Barni et. al., team members confidently proposed a method to watermark MPEG-4 video objects in a very efficient manner. The proposed method embeds the watermark in each video object by posing a particular relationship between some predefined pairs of quantized DCT coefficients in the luminance block. Watermark is equally embedded into Inter and Intra macro blocks of the video [18] . Satyen Biswas et. al., team works on uncompressed video and also on the compressed video sequences. The main theme is to improve the authentication of multimedia objects and it is done using watermarking in the GOP. Drift Compensation method is used to predict the changes between successive frames in the video clips. Blind detection of watermark is done using estimation technique and it is very robust to attacks [19].

Karen Su et. al., presents a hypothetical structure for the linear collusion analysis of digital video watermarking, derive new statistical invisibility theorem, collusion - resistance theorem and practical design rules. Here the design of a copyright protection system for MPEG2 videos and attacks of multiple frames linear collusion like a) Linear Collusion, b) Statistical Invisibility are also discusses [20].

Yulin Wang and Alan Pearmain, presents MPEG2 video blind watermarking and this is very robust to geometric attaks. The proposed method is not restricted to MPEG2 alone it can be suited for DCT based coding videos [21].

Jing Zhang et. al., presents a robust video watermarking of H.264/AVC where pre - processing of the gray scale watermark is done to obtain the $1 \mathrm{D}$ output sequence. This obtained pattern is embedded into a compressed video. It achieves high robustness to various signal processing attacks and good visual quality [22].

Maneli Noorkami and Russell M. Mersereau, introduced a structure of robust video watermarking of H.264 video to 
provide copyright protection and authentication. In this work the authors uses 4X4 DCT to increase the payload of the watermark and also uses a key dependent algorithm to have a visual watermarking capacity. This work provides good robustness to various attacks [23].

Alper Loz and Aydin Alatan, compares their work named spatio - temporal watermarking of video by using HVS with the other two algorithms i.e. first one is based on spatial sensitivity of HVS and the other uses only the HVS characteristics. It is present that the robustness of the watermark can be improved by integrating temporal characteristics. This work is robust against common temporal signal processing operations [24].

Siyue Chen and Henry Leung, presents disordered semi fragile watermarking for video authentication used in scrutiny applications, here they used raw video data for processing. Mapping is carried on GOP and frame index separately. This method is robust to common spatial processing [25].

Lino E. Coria et. al., discourage camcorder in theater to avoid the piracy of the videos. The team developed a system using dual tree complex wavelet transform for watermarking, the video watermarking is performed such that if the watermark is displayed the video will not be played in a player it is very robust to geometric distortions and lossy compressions [26].

Young-Yoon Lee et. al., presents two different temporal feature modulation algorithms where in the first one is the watermark is embedded in skipping selected frames and the second is to find the centers of gravity in the blocks to embed the watermark. It is robust to compression and temporal attacks [27].

R. Reyes et. al., proposes a video watermarking system where the watermark is logo image of the owner. In this work the video sequences are segmented in every frame and the watermark logo is embedded into the frames randomly. The security is increased by using a logo binary pattern mapped to a noise like binary pattern before embedding this process is robust against several attacks [28].

Alper Koz et. al., team presents watermarking of free view video in which the watermark is embedded with three different factors where the first one global scaling factor, second one is image processed through high pass filter and the last watermark sequence with zero mean and unit variance. The watermark is embedded in every frame of the video and it is robust to geometric and compression attacks [29].

Min - Jeong et. al., presents a very good approach to avoid the pirates copying the digital cinema using camcorder, this technique provides robust watermark recognition in opposition to camcorder capture and also to extract data about the place and time of piracy. It helps to find out the persons performing pirates by using position estimate model approach [30].

Liyun Wang et. al., proposes real time video watermarking scheme on compressed videos like MPEG1, MPEG2 and it can be applied for MPEG4 and H.264 because DWT domain could directly acquired from block DCT's of any size. This work is very robust to geometric attacks and also used for hiding of data [31].
Andras Boho et. al., presents video security and tackles cryptography and signal processing operations each other. It uses little encryption techniques in tradeoff between preserved functionality and security. The encryption of data sets in H.264/AVC and HEVC achieves consistently low SSIM values. The watermark is robust against signal processing operations and transcoding. It achieves better tradeoff between robustness, perceptibility and payload [32].

Mehdi Fallahpour et. al., presents a sensible system of digital video watermarking for tamper detection of compressed videos and authentication. The embedding is done in LNZ DCT blocks and extracting of watermarks are integrated with the coding and decoding of video codec. The cryptography technique is used to improve the security of the system [33].

Md. Asikuzzaman et. al., team presents three different versions of robust blind video watermarking based on DT CWT. First the watermark is embedded in the level of three coefficient of a three level DT - CWT decomposition of chrominance channel to make robust to geometric attacks [34].

In Table 3 and 4 the detailed information of the existing video watermarking techniques in terms of videos been used, watermarking domains, attacks and experimental results.

\section{STATISTICS OF VIDEO WATERMARKING SYSTEM}

The below figures 4,5 and 6 shows the statistics of the video watermarking systems been used in research where the compressed videos utilization is more compared with the uncompressed video or raw videos. The main reason is when the raw video is processed with watermark embedding process the data is getting effected and the quality decreases as such psnr value is decreased. In figure 5 the type of domain usage statistics is performed and in figure 6 psnr of various systems are discussed.

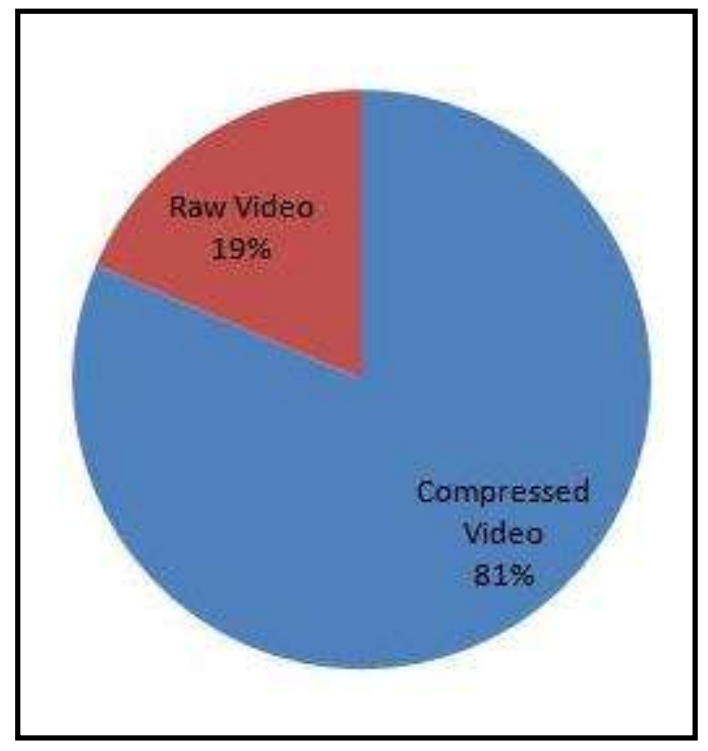

Figure 4 Percentage of Video formats used 
International Journal of Computer Applications Technology and Research

Volume 5- Issue 5, 295 - 303, 2016, ISSN:- 2319-8656

Table 3. Detailed video watermarking domains

\begin{tabular}{|c|c|c|c|}
\hline S.No & Authors & $\begin{array}{c}\text { Type of video } \\
\text { used }\end{array}$ & $\begin{array}{c}\text { Video } \\
\text { Watermarking } \\
\text { Domain }\end{array}$ \\
\hline 1 & $\begin{array}{c}\text { Frank } \\
\text { Hartung and } \\
\text { Bernd Girod } \\
\text { [4]. }\end{array}$ & $\begin{array}{c}\text { Compressed } \\
\text { MPEG2 Video }\end{array}$ & $\begin{array}{c}\text { Spatial and } \\
\text { Frequency } \\
\text { Domain: DCT }\end{array}$ \\
\hline 2 & $\begin{array}{l}\text { Chiou - Ting } \\
\text { Hsu and } \mathrm{Ja}- \\
\text { Ling } \mathrm{Wu} \mathrm{[5]}\end{array}$ & $\begin{array}{l}\text { Compressed } \\
\text { MPEG Video }\end{array}$ & $\begin{array}{c}\text { Frequency } \\
\text { domain: DCT }\end{array}$ \\
\hline 3 & $\begin{array}{c}\text { Frank } \\
\text { Hartung and } \\
\text { Bernd Girod } \\
{[6]}\end{array}$ & $\begin{array}{l}\text { Raw video and } \\
\text { Compressed } \\
\text { MPEG2 Video }\end{array}$ & $\begin{array}{c}\text { Spatial and } \\
\text { Frequency } \\
\text { domain:DCT }\end{array}$ \\
\hline 4 & $\begin{array}{l}\text { Mitchell D. } \\
\text { Swanson et. } \\
\text { al. [7] }\end{array}$ & $\begin{array}{l}\text { Compressed } \\
\text { Video data }\end{array}$ & $\begin{array}{c}\text { Spatial and } \\
\text { Frequency domain }\end{array}$ \\
\hline 5 & $\begin{array}{c}\text { Tae - Yun } \\
\text { Chung et. } \\
\text { al.,[8] }\end{array}$ & $\begin{array}{c}\text { Compressed } \\
\text { MPEG2 Video }\end{array}$ & $\begin{array}{c}\text { Frequency } \\
\text { domain: DCT }\end{array}$ \\
\hline 6 & $\begin{array}{c}\text { Christoph } \\
\text { Busch et. } \\
\text { al.,[9]. }\end{array}$ & $\begin{array}{c}\text { Compressed } \\
\text { MPEG2 Video }\end{array}$ & $\begin{array}{c}\text { Spatial and } \\
\text { Frequency } \\
\text { domain: Modified } \\
\text { Koch - Zhao } \\
\text { Algorithm (New } \\
\text { DCT \& IDCT } \\
\text { Algorithms) }\end{array}$ \\
\hline 7 & $\begin{array}{l}\text { Wenwu Zhu } \\
\text { et. al.,[10] }\end{array}$ & $\begin{array}{c}\text { JPEG Image } \\
\text { and MPEG2 } \\
\text { Video }\end{array}$ & $\begin{array}{c}\text { Frequency } \\
\text { Domain: DWT }\end{array}$ \\
\hline 8 & $\begin{array}{l}\text { Xiamu Niu } \\
\text { et. al., [12] }\end{array}$ & $\begin{array}{l}\text { Compressed } \\
\text { MPEG Video }\end{array}$ & $\begin{array}{c}\text { Frequency } \\
\text { domain: DWT }\end{array}$ \\
\hline 9 & $\begin{array}{l}\text { T. Brandao } \\
\text { et. al., [13] }\end{array}$ & $\begin{array}{c}\text { Compressed } \\
\text { MPEG2 Video } \\
\end{array}$ & $\begin{array}{l}\text { Spatial domain: } \\
\text { Spread Spectrum } \\
\end{array}$ \\
\hline 10 & $\begin{array}{c}\text { Emmanuel } \\
\text { Garcia et. al. } \\
{[14] .}\end{array}$ & 3D Objects & $\begin{array}{l}\text { Spatial Domain: } \\
\text { Pseudorandom } \\
\text { noise is added as } \\
\text { watermark }\end{array}$ \\
\hline 11 & $\begin{array}{c}\text { Shih }- \text { Wel } \\
\text { Sun and Pao } \\
\text { - Chi Chang } \\
{[15]}\end{array}$ & $\begin{array}{c}\text { Uncompressed } \\
\text { Video }\end{array}$ & Spatial Domain \\
\hline 12 & $\begin{array}{c}\text { Gwenael } \\
\text { Doerr and } \\
\text { Jean - Luc } \\
\text { Dugelay, } \\
\text { [16]. }\end{array}$ & $\begin{array}{c}\text { MPEG2 } \\
\text { Compressed } \\
\text { Video }\end{array}$ & Spatial Domain \\
\hline 13 & $\begin{array}{c}\text { Eugene T. } \\
\text { Lin et. } \\
\text { al.,[17] }\end{array}$ & $\begin{array}{l}\text { Uncompressed } \\
\text { Video }\end{array}$ & Spatial Domain \\
\hline 14 & $\begin{array}{c}\text { Mauro Barni } \\
\text { et. al. [18] }\end{array}$ & $\begin{array}{l}\text { Compressed } \\
\text { MPEG-4 video }\end{array}$ & Transform domain \\
\hline
\end{tabular}

\begin{tabular}{|c|c|c|c|}
\hline 15 & $\begin{array}{l}\text { Satyen Biswas } \\
\text { et. al., [19] }\end{array}$ & $\begin{array}{l}\text { Uncompressed } \\
\text { (DAVI) and } \\
\text { Compressed } \\
\text { MPEG2 Video }\end{array}$ & $\begin{array}{c}\text { Spatial domain } \\
\& \\
\text { Transform } \\
\text { domain (DCT) } \\
\end{array}$ \\
\hline 16 & $\begin{array}{c}\text { Yulin Wang and } \\
\text { Alan Pearmain, } \\
{[21]}\end{array}$ & $\begin{array}{l}\text { Compressed } \\
\text { MPEG2 video }\end{array}$ & $\begin{array}{c}\text { Transform } \\
\text { domain: DCT }\end{array}$ \\
\hline 17 & $\begin{array}{l}\text { Jing Zhang et. } \\
\text { al. [22] }\end{array}$ & $\begin{array}{c}\text { Compressed } \\
\text { Video } \\
\text { H.264/AVC } \\
\end{array}$ & $\begin{array}{c}\text { Transform } \\
\text { domain: DCT }\end{array}$ \\
\hline 18 & $\begin{array}{c}\text { Maneli } \\
\text { Noorkami and } \\
\text { Russell M. } \\
\text { Mersereau, [23] }\end{array}$ & $\begin{array}{l}\text { Compressed } \\
\text { Video H.264 }\end{array}$ & $\begin{array}{c}\text { Transform } \\
\text { Domain: DCT }\end{array}$ \\
\hline 19 & $\begin{array}{c}\text { Alper Loz and } \\
\text { Aydin Alatan, } \\
{[24]}\end{array}$ & $\begin{array}{c}\text { Compressed } \\
\text { video ITU H.263 }\end{array}$ & $\begin{array}{c}\text { Spatial and } \\
\text { Transform } \\
\text { domain: DCT }\end{array}$ \\
\hline 20 & $\begin{array}{c}\text { Siyue Chen and } \\
\text { Henry Leung, } \\
{[25]}\end{array}$ & Raw video (AVI) & $\begin{array}{c}\text { Transform } \\
\text { domain: DCT }\end{array}$ \\
\hline 21 & $\begin{array}{l}\text { Lino E. Coria } \\
\text { et. al., [26] }\end{array}$ & $\begin{array}{c}\text { Standard Video } \\
\text { files of QCIF } \\
(176 \text { X 144) }\end{array}$ & $\begin{array}{c}\text { Transform } \\
\text { domain DT- } \\
\text { CWT and } \\
\text { DWT. }\end{array}$ \\
\hline 22 & $\begin{array}{l}\text { Young-Yoon } \\
\text { Lee et. al,[27] }\end{array}$ & $\begin{array}{c}\text { Compressed } \\
\text { Video } \\
\text { H.264/AVC } \\
\end{array}$ & Spatial domain \\
\hline 23 & $\begin{array}{l}\text { R. Reyes et. } \\
\text { al.,[28] }\end{array}$ & $\begin{array}{c}\text { Compressed } \\
\text { Video }\end{array}$ & $\begin{array}{c}\text { Transform } \\
\text { domain:DWT } \\
\end{array}$ \\
\hline 24 & $\begin{array}{c}\text { Alper Koz et. } \\
\text { al.,[29] }\end{array}$ & TV Video Signal & Spatial domain \\
\hline 25 & $\begin{array}{c}\text { Min - Jeong et. } \\
\text { al., [30] }\end{array}$ & $\begin{array}{l}\text { Watermarking the } \\
\text { Pirates camcorder }\end{array}$ & Spatial Domain \\
\hline 26 & $\begin{array}{c}\text { Liyun Wang et. } \\
\text { al.,[31] }\end{array}$ & $\begin{array}{c}\text { MPEG1 and } \\
\text { MPEG2 Videos }\end{array}$ & $\begin{array}{c}\text { Frequency } \\
\text { domain: DCT } \\
\text { \& DWT }\end{array}$ \\
\hline 27 & $\begin{array}{c}\text { Andras Boho et. } \\
\text { al., [32] }\end{array}$ & $\begin{array}{c}\text { H.264/AVC and } \\
\text { HEVC video } \\
\text { formats }\end{array}$ & $\begin{array}{c}\text { Spatial and } \\
\text { Frequency } \\
\text { domains } \\
\end{array}$ \\
\hline 28 & $\begin{array}{c}\text { Mehdi } \\
\text { Fallahpour et. } \\
\text { al., [33] }\end{array}$ & $\begin{array}{l}\text { H.264/AVC video } \\
\text { formats }\end{array}$ & $\begin{array}{c}\text { Spatial and } \\
\text { Frequency } \\
\text { domain }\end{array}$ \\
\hline 29 & $\begin{array}{c}\text { Md. } \\
\text { Asikuzzaman et. } \\
\text { al.,[34] }\end{array}$ & $\begin{array}{l}\text { MPEG video } \\
\text { formats }\end{array}$ & $\begin{array}{c}\text { Frequency } \\
\text { domain: DT } \\
\text { CWT } \\
\end{array}$ \\
\hline
\end{tabular}

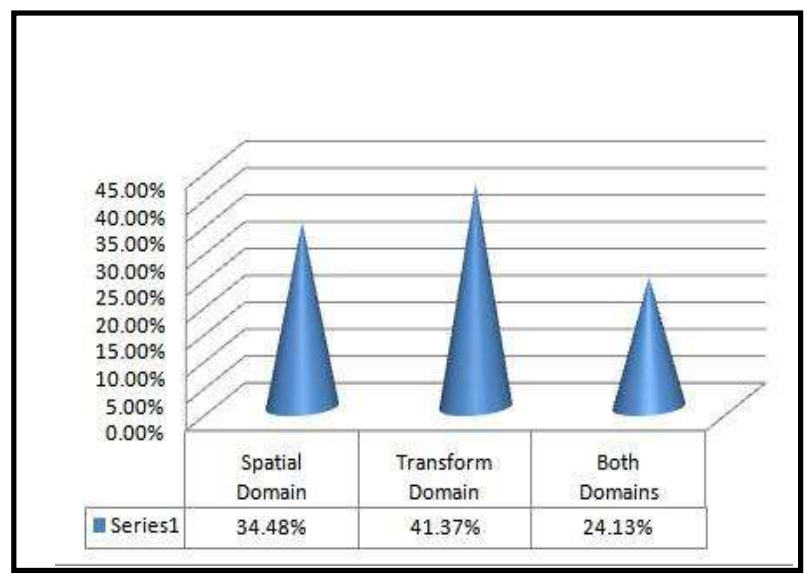

Figure 5 Percentage of used Domains 
Table 4 Video Watermarking Attacks and Results

\begin{tabular}{|c|c|c|c|}
\hline S.No & Authors & $\begin{array}{c}\text { Attacks } \\
\text { performed }\end{array}$ & $\begin{array}{l}\text { Experimental } \\
\text { Results }\end{array}$ \\
\hline 1 & $\begin{array}{c}\text { Frank } \\
\text { Hartung and } \\
\text { Bernd Girod } \\
\text { [4]. }\end{array}$ & $\begin{array}{l}\text { Robust against } \\
\text { Un-attempted } \\
\text { and Attempted } \\
\text { attacks }\end{array}$ & $\begin{array}{l}15 \text { to } 30 \% \text { of } \\
\text { DCT coefficients } \\
\text { are altered. }\end{array}$ \\
\hline 2 & $\begin{array}{l}\text { Chiou - Ting } \\
\text { Hsu and } \mathrm{Ja}- \\
\text { Ling } \mathrm{Wu} \mathrm{[5]}\end{array}$ & $\begin{array}{c}\text { Robust to } \\
\text { Cropping and } \\
\text { MPEG } \\
\text { Compression }\end{array}$ & $\begin{array}{l}\text { PSNR is } \\
44.63 \mathrm{~dB} \\
\mathrm{NC}=1\end{array}$ \\
\hline 3 & $\begin{array}{c}\text { Frank } \\
\text { Hartung and } \\
\text { Bernd Girod } \\
{[6]}\end{array}$ & $\begin{array}{c}\text { Robust to } \\
\text { temporal attacks } \\
\text { and MPEG } \\
\text { compression }\end{array}$ & $\begin{array}{c}\text { Chip Rate is } \\
\quad 633,600 \\
\text { Error is } 0.0194\end{array}$ \\
\hline 4 & $\begin{array}{l}\text { Mitchell D. } \\
\text { Swanson et. } \\
\text { al. [7] }\end{array}$ & $\begin{array}{c}\text { Robust to } \\
\text { several Video } \\
\text { degradation and } \\
\text { distortion. }\end{array}$ & $\begin{array}{c}\text { Avg. PSNR is } \\
36.9 \mathrm{~dB}\end{array}$ \\
\hline 5 & $\begin{array}{c}\text { Tae - Yun } \\
\text { Chung et. } \\
\text { al.,[8] }\end{array}$ & $\begin{array}{c}\text { Robust to } \\
\text { Cropping and } \\
\text { MPEG } \\
\text { Compression }\end{array}$ & $\begin{array}{c}\text { Watermark } \\
\text { Extraction } \\
\text { Accuracy is 97\% } \\
\text { Avg. PSNR is } \\
32.5\end{array}$ \\
\hline 6 & $\begin{array}{l}\text { Christoph } \\
\text { Busch et. } \\
\text { al.,[9]. }\end{array}$ & $\begin{array}{l}\text { Robust against } \\
\text { MPEG2 } \\
\text { encoding } \\
\text { Restricted to } \\
\text { some well of } \\
\text { geometric } \\
\text { attacks }\end{array}$ & $\begin{array}{c}\text { Transparent } \\
\text { Watermarking is } \\
\text { attained } \\
\text { Data Rates are } \\
\text { 4Mbps and } \\
6 \mathrm{Mbps} \\
\text { Percentage of } \\
\text { Corrected bits is } \\
\text { above } 90 \%\end{array}$ \\
\hline 7 & $\begin{array}{c}\text { Wenwu Zhu } \\
\text { et. al.,[10] }\end{array}$ & $\begin{array}{c}\text { Robust to } \\
\text { Image/ Video } \\
\text { compression and } \\
\text { digital } \\
\text { halftoning. }\end{array}$ & $\begin{array}{c}\text { PSNR(Image) is } \\
42.77 \mathrm{~dB} \\
\text { PSNR(Image) } \\
\text { after SPIHT } \\
\text { compression is } \\
33.48 \mathrm{~dB} \\
\text { PSNR of Video } \\
\text { first frame is } \\
29.99 \mathrm{~dB} \\
\text { Computational } \\
\text { saving is } 87.5 \%\end{array}$ \\
\hline 8 & $\begin{array}{l}\text { Xiamu Niu } \\
\text { et. al., [12] }\end{array}$ & $\begin{array}{l}\text { Robust to Frame } \\
\text { dropping, } \\
\text { averaging and } \\
\text { lossy } \\
\text { compression }\end{array}$ & $\begin{array}{l}\text { PSNR values of } \\
\text { original and } \\
\text { waternarked } \\
\text { frames of size } \\
352 \times 240 \text { is } \\
32.49\end{array}$ \\
\hline 9 & $\begin{array}{l}\text { T. Brandao } \\
\text { et. al., [13] }\end{array}$ & $\begin{array}{c}\text { Robust to } \\
\text { compression } \\
\text { attack }\end{array}$ & $\begin{array}{c}\text { Presents a good } \\
\text { Performance vs. } \\
\text { simplicity trade } \\
\text { off. }\end{array}$ \\
\hline 10 & $\begin{array}{c}\text { Emmanuel } \\
\text { Garcia et. al. } \\
{[14] .}\end{array}$ & $\begin{array}{c}\text { Robust to } \\
\text { geometric } \\
\text { disturbances }\end{array}$ & $\begin{array}{l}\text { Better tradeoff } \\
\text { between capacity } \\
\text { and robustness is } \\
\text { achieved. } \\
\text { Blind } \\
\text { Watermarking is } \\
\text { done }\end{array}$ \\
\hline
\end{tabular}

\begin{tabular}{|c|c|c|c|}
\hline 11 & $\begin{array}{c}\text { Shih }- \text { Wel } \\
\text { Sun and Pao } \\
\text { - Chi Chang } \\
\text { [15] }\end{array}$ & $\begin{array}{c}\text { Robust to } \\
\text { temporal attacks } \\
\text { like transposition, } \\
\text { dropping and } \\
\text { insertion. }\end{array}$ & $\begin{array}{c}\text { The accuracy of } \\
\text { frame detection is } \\
\text { from } 72.41 \% \text { to } \\
98.15 \% \text {. }\end{array}$ \\
\hline 12 & $\begin{array}{c}\text { Gwenael } \\
\text { Doerr and } \\
\text { Jean - Luc } \\
\text { Dugelay, } \\
\text { [16]. }\end{array}$ & $\begin{array}{c}\text { Robustness is } \\
\text { achieved for every } \\
\text { attack step by step }\end{array}$ & $\begin{array}{c}\text { Four modules are } \\
\text { developed in } \\
\text { spread spectrum }\end{array}$ \\
\hline 13 & $\begin{array}{l}\text { Eugene T. } \\
\text { Lin et. } \\
\text { al.,[17] }\end{array}$ & $\begin{array}{l}\text { Robust against } \\
\text { temporal } \\
\text { Synchronization } \\
\text { attacks }\end{array}$ & $\begin{array}{l}\text { Developed a state } \\
\text { machine key } \\
\text { generator. } \\
\text { Flicker is } \\
\text { generated in the } \\
\text { video due to } \\
\text { watermark }\end{array}$ \\
\hline 14 & $\begin{array}{c}\text { Mauro Barni } \\
\text { et. al. [18] }\end{array}$ & $\begin{array}{l}\text { Robust against Bit } \\
\text { rate decreasing, } \\
\text { Frame dropping, }\end{array}$ & $\begin{array}{l}\text { Synchronization is } \\
\text { achieved. } \\
\text { Confidence values } \\
\text { are high when } \\
\text { wrong key is used. }\end{array}$ \\
\hline 15 & $\begin{array}{c}\text { Satyen } \\
\text { Biswas et. } \\
\text { al., [19] }\end{array}$ & $\begin{array}{l}\text { Robust against } \\
\text { Spatial and } \\
\text { temporal Attacks }\end{array}$ & $\begin{array}{c}\text { Average } \mathrm{NC}= \\
0.95 \text { and decreases } \\
\text { with increase in } \\
\text { frame dropping. }\end{array}$ \\
\hline 16 & $\begin{array}{c}\text { Yulin Wang } \\
\text { and Alan } \\
\text { Pearmain, } \\
{[21]}\end{array}$ & $\begin{array}{c}\text { Robust to } \\
\text { geometric attacks }\end{array}$ & $\begin{array}{c}\text { Q Step is } 6,8 \text { and } \\
12 . \\
\text { Error rate is below } \\
1.7 \%\end{array}$ \\
\hline 17 & $\begin{array}{l}\text { Jing Zhang } \\
\text { et. al. [22] }\end{array}$ & $\begin{array}{c}\text { Robust to } \\
\text { Transcoding and } \\
\text { Signal processing } \\
\text { Attacks like } \\
\text { Gaussian low pass } \\
\text { filtering } \\
\text { Additive Gaussian } \\
\text { Noise(Variance is } \\
\text { 0.75) } \\
\text { Circular averaging } \\
\text { filter } \\
\text { Unsharp Contrast } \\
\text { enhancement }\end{array}$ & $\begin{array}{c}\text { Correlation values } \\
\text { for watermarked } \\
\text { video is } 0.93 \text {, } \\
\text { Correlation after } \\
\text { transcoding }\left(1 / 3^{\text {rd }}\right. \\
\text { Bit rate) is } 0.50 \\
\text { Correlation after } \\
\text { Circular filtering is } \\
0.87 \\
\text { Correlation after } \\
\text { Contrast } \\
\text { enhancement is } \\
083 \\
\text { Correlation after } \\
\text { Gaussian Noise is } \\
0.75\end{array}$ \\
\hline 18 & $\begin{array}{c}\text { Maneli } \\
\text { Noorkami } \\
\text { and Russell } \\
\text { M. } \\
\text { Mersereau, } \\
\text { [23] }\end{array}$ & $\begin{array}{c}\text { Robust to } \\
\text { Several common } \\
\text { signal processing } \\
\text { attacks }\end{array}$ & $\begin{array}{c}\text { High Payload } \\
\text { Average } \\
\text { Correlation factor } \\
\text { is } 0.997\end{array}$ \\
\hline 19 & $\begin{array}{l}\text { Alper Loz } \\
\text { and Aydin } \\
\text { Alatan, [24] }\end{array}$ & $\begin{array}{c}\text { Robust to } \\
\text { Several common } \\
\text { signal processing } \\
\text { attacks } \\
\text { Transcoding } \\
\text { attacks }\end{array}$ & $\begin{array}{c}\text { Average } \\
\text { PSNR(Foreman) } \\
\text { is 39dB } \\
\text { Avg. PSNR } \\
\text { (Mother } \\
\text { Sequence) is } \\
\text { 43dB. }\end{array}$ \\
\hline
\end{tabular}




\begin{tabular}{|c|c|c|c|}
\hline 20 & $\begin{array}{l}\text { Siyue Chen } \\
\text { and Henry } \\
\text { Leung, [25] }\end{array}$ & $\begin{array}{c}\text { Robust to JPEG } \\
\text { Compression } \\
\text { Median Filtering } \\
\text { Contrast } \\
\text { Enhancement }\end{array}$ & $\begin{array}{c}\text { Data Payloads } \\
\text { are } 32 \text { and } 1024 \\
\text { bits } \\
\text { PSNR is } 42 \mathrm{~dB}\end{array}$ \\
\hline 21 & $\begin{array}{c}\text { Lino E. Coria } \\
\text { et. al., [26] }\end{array}$ & $\begin{array}{c}\text { Robust to } \\
\text { Attacks } \\
\text { Fragile to Joint } \\
\text { Attack }\end{array}$ & $\begin{array}{c}\text { Avg. PSNR is } \\
41 \mathrm{~dB}\end{array}$ \\
\hline 22 & $\begin{array}{l}\text { Young-Yoon } \\
\text { Lee et. al,[27] }\end{array}$ & $\begin{array}{c}\text { Robust against } \\
\text { Compression } \\
\text { and temporal } \\
\text { attacks }\end{array}$ & $\begin{array}{c}\text { Frames rate is } \\
29.977 \text { or } 23.976 \\
\text { fps. } \\
\text { PSNR is } 31 \mathrm{~dB}\end{array}$ \\
\hline 23 & $\begin{array}{l}\text { R. Reyes et. } \\
\text { al.,[28] }\end{array}$ & $\begin{array}{c}\text { Robust against } \\
\text { different Noisy } \\
\text { attacks } \\
\end{array}$ & $\mathrm{NC}=0.95$ \\
\hline 24 & $\begin{array}{l}\text { Alper Koz et. } \\
\text { al.,[29] }\end{array}$ & $\begin{array}{c}\text { Robust to } \\
\text { AWGN noise } \\
\text { compression } \\
\text { Attacks } \\
\text { Geometric } \\
\text { Attacks } \\
\end{array}$ & $\begin{array}{c}\text { Best NC=0.875 } \\
\text { Avg. Noise } \\
\text { PSNR is } 42.11\end{array}$ \\
\hline 25 & $\begin{array}{l}\text { Min - Jeong } \\
\text { et. al., [30] }\end{array}$ & $\begin{array}{l}\text { Robust to } \\
\text { camcorder } \\
\text { capture } \\
\text { Geometric } \\
\text { distortions } \\
\text { Signal } \\
\text { Processing } \\
\text { distortions } \\
\end{array}$ & $\begin{array}{l}\text { Avg PSNR is } \\
46.0 \mathrm{~dB} \\
\text { Avg PSNR is } \\
45 \mathrm{~dB} \text { for HD } \\
\text { videos }\end{array}$ \\
\hline 26 & $\begin{array}{c}\text { Liyun Wang } \\
\text { et. al.,[31] }\end{array}$ & $\begin{array}{l}\text { Robust against } \\
\text { cropping and } \\
\text { rotation attacks }\end{array}$ & $\begin{array}{l}\text { Avg. Bit Error } \\
\text { Rate (BER) is } \\
\text { almost negligible } \\
\text { i.e. Zero for } \\
\text { many attacks. } \\
\text { Avg. BER is } 3.3 \\
\text { for H.264 } \\
\text { Compression }\end{array}$ \\
\hline 27 & $\begin{array}{c}\text { Andras Boho } \\
\text { et. al., [32] }\end{array}$ & $\begin{array}{l}\text { Robust against } \\
\text { Signal } \\
\text { Processing } \\
\text { attacks } \\
\text { Transcoding } \\
\text { Compression }\end{array}$ & $\begin{array}{l}\text { Quantization } \\
\text { Index } \\
\text { Modulation is } \\
\text { employed } \\
\text { Avg. } \\
\text { H.264/AVC } \\
\text { PSNR is 55dB } \\
\\
\text { Avg. BER is } \\
0.011\end{array}$ \\
\hline 28 & $\begin{array}{c}\text { Mehdi } \\
\text { Fallahpour et. } \\
\text { al., [33] }\end{array}$ & $\begin{array}{l}\text { Robust to } \\
\text { common video } \\
\text { processing } \\
\text { operations }\end{array}$ & $\begin{array}{c}\text { PSNR is } 50.54 \\
\text { PSNR } \\
\text { degradation is } \\
0.88 \mathrm{~dB} \\
\text { Structural } \\
\text { Similarity Index } \\
\text { Decreases is } \\
0.0090 \\
\text { Bit Correct rate } \\
\text { is } 0.71 \text { to } 0.88\end{array}$ \\
\hline 29 & $\begin{array}{c}\text { Md. } \\
\text { Asikuzzaman } \\
\text { et. al.,[34] }\end{array}$ & $\begin{array}{c}\text { Robust to } \\
\text { Compression } \\
\text { and Geometric } \\
\text { Attacks } \\
\text { Temporal } \\
\text { Synchronization } \\
\text { Attacks } \\
\end{array}$ & $\begin{array}{l}\text { SSLD, SDLD } \\
\text { and KDLD } \\
\text { methods were } \\
\text { proposed }\end{array}$ \\
\hline
\end{tabular}

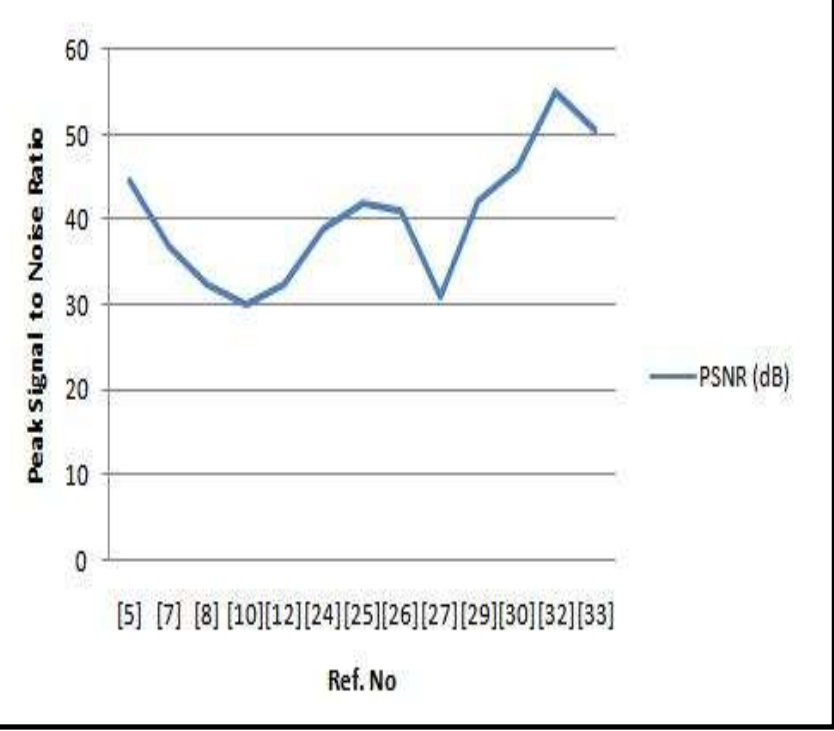

Figure 6 PSNR values of Video watermarking systems

\section{CONCLUSION}

In this video watermarking survey [4] to [34] are using compressed video except [14], [15], [17] and [25] where these uses un-compressed video or raw video for video watermarking. In [3] and [19] video watermarking is for both Compressed and Uncompressed video formats. The best technique for the compressed video watermarking in terms of PSNR can be attained by using parametric lattice quantization index modulation (QIM) proposed by Andras Boho et. al., [32] and also proved that Structural Similarity (SSIM) index is considered as better parameter than that of PSNR to calculate the quality degradation [32]. In the attempt to provide robustness against various video attacks Keyless Dynamic Level Detection (KDLD) method proposed by Md. Asikuzzaman et. al.,[34] provides best robustness to the various attacks compared with other methods. Min - Jeong et. al., [30] gives the best position estimating model (PEM) with a mean absolute error (MAE) to prevent pirated copies of digital cinema captured by tripod mounted SONY HDR FX 1 camcorder in real theaters. The best technique for uncompressed video is chaotic semi fragile watermarking which gives PSNR of $42 \mathrm{~dB}$ proposed by Siyue Chen and Henry Leung [25].

\section{REFERENCES}

[1] Gwenael Doerr and Jean-Luc, "Security Pitfalls of Frame by Frame Approaches to Video Watermarking", IEEE Transactions on Signal Processing, Supplement on secure media, October 2004.

[2] Stefan Katzenbeisser and Fabien A.P. Petitcolas, "Computer Security Series: Information Hiding Techniques for Steganography and Digital Watermarking", Artech House Boston, London.

[3] Ali Mohammad Al - Haj, "Premier Reference Source Advanced Techniques in Multimedia Watermarking: Image, Video and Audio Applications" Princess Sumaya University for Technology, Jordan. 
[4] Frank Hartung and Bernd Girod, "Copyright Protection in Video Delivery Networks by Watermarking of Pre Compressed Video", Multimedia Applications, Services and Techniques - ECMAST' 97, Springer Lecturer Notes in Computer Science, Vol. 1242, pp. $423-436$.

[5] Chiou - Ting Hsu and Ja - Ling Wu, "DCT based Watermarking for Video", IEEE Transactions on Consumer Electronics, Vol.44, No.1, Feb 1998, pp. 206 -216 .

[6] Frank Hartung and Bernd Girod, "Watermarking of Uncompressed and Compressed Video", Elsevier Preprint, Vol. 66, No. 3, May 1998, pp. 283 - 301.

[7] Mitchell D. Swanson et. al. "Multiresolution Scene Based Video Watermarking using Perceptual Models", IEEE Journal on Selected areas in Communications, Vol. 16, No. 4, May 1998, pp. 540 - 550.

[8] Tae - Yun Chung et. al., "Digital Watermarking for Copyright Protection of MPEG2 Compressed Video", IEEE Transactions on Consumer Electronics, Vol. 44, No. 3, August 1998, pp. 895 - 901.

[9] Christoph Busch et. al., "Digital Watermarking: From Concepts to Real time Video Applications", Image Security, IEEE Computer Graphics and Applications, January/February 1999, pp. $25-35$.

[10] Wenwu Zhu et. al., "Multiresolution Watermarking for Images and Video", IEEE, Transactions on Circuits and Systems for Video Technology, Vol. 9, No. 4, June 1999, pp. $545-550$.

[11] Gerhard C. Langelaar et. al., "A State of the Art Overview: Watermarking Digital Image and Video Data", IEEE Signal Processing Magazine, September 2000, pp. $20-46$.

[12] Xiamu Niu et. al., "Multiresoultion Watermarking for Video based on Gray Level Digital Watermark", IEEE Transaction on Customer Electronics, Vol. 46, No. 2, May 2000, pp. $375-384$.

[13] T. Brandao et. al., "Diversity Enhancement of Coded Spread Spectrum Video Watermarking", Wireless Personal Communications, Kulwer Academic Publishers, 2002, pp. $93-104$.

[14] Emmanuel Garcia et. al., "Texture Based Watermarking of 3D Video Objects", IEEE transaction on Circuits and Systems for Video Technology, Vol. 13, No. 8, August 2003, pp. $853-866$.

[15] Shih - Wel Sun and Pao - Chi Chang, "Video Watermarking Synchronization based on Profile Statistics", IEEE A\&E Systems Magazine, May 2004, pp. $21-25$.

[16] Gwenael Doerr and Jean - Luc Dugelay, "Security Pitfalls of Frame by Frame Approaches to Video Watermarking”, IEEE Transactions on Signal
Processing, Vol. 52, No. 10, October 2004, pp. 2955 2964.

[17] Eugene T. Lin et. al., "Temporal Synchronization in Video Watermarking", IEEE Transactions on Signal Processing, Vol. 52, No. 10, October 2004, pp. 3007 3022.

[18] Mauro Barni et. al., "Watermarking of MPEG-4 Video Objects”, IEEE Transactions on multimedia, Vol. 7, No. 1, February 2005 , pp. $23-32$.

[19] Satyen Biswas et. al., "An Adaptive Compressed MPEG2 Video Watermarking Scheme", IEEE Transactions on Instrumentation and Measurement, Vol. 54, No. 5, October 2005, pp. $1853-1861$.

[20] Karen Su et. al., "Statistical Invisibility for Collusion Resistant Digital Video Watermarking", IEEE Transactions on Multimedia, Vol. 7, No. 1, February 2005, pp $43-51$.

[21] Yulin Wang and Alan Pearmain, "Blind MPEG2 Video Watermarking Robust Against Geometric Attacks: A set of Approaches in DCT domain", IEEE Transactions on Image Processing, Vol. 15, No. 6, June 2006, pp. 1536 1543.

[22] Jing Zhang et. al.,"Robust Video Watermarking of H.264/AVC", IEEE Transactions on Circuits and Systems-II:Express Briefs, Vol. 54, No. 2, February 2007, pp. $205-209$.

[23] Maneli Noorkami and Russell M. Mersereau, "A Framework for Robust Watermarking of H.264 Encoded Video with Controllable Detection Performance", IEEE Transactions on Information Forensics and Security, Vol. 2, No. 1, March 2007, pp. $14-23$.

[24] Alper Loz and Aydin Alatan, "Oblivious Spatio Temporal Watermarking of Digital Video by Exploiting the Human Visual System", IEEE Transactions on Circuits and Systems for Video Technology, Vol. 18, No. 3, March 2008, pp. $326-337$.

[25] Siyue Chen and Henry Leung, "Chaotic Watermarking for Video Authentication in Surveillance Applications", IEEE Transactions on Circuits and Systems for Video Technology”, Vol. 18, No. 5, May 2008, pp. 704 - 709.

[26] Lino E. Coria et. al., "A Video Watermarking Scheme based on the Dual Tree Complex Wavelet Transform", IEEE Transactions on Information Forensics and Security, Vol. 3, No. 3, September 2008, pp. 466 - 474

[27] Young-Yoon Lee et. al, "Temporal Feature Modulation for Video Watermarking", IEEE Transactions on Circuits and Systems for Video Technology, Vol. 19, No. 4, April 2009, pp. $603-608$.

[28] R. Reyes et. al., "Digital Video Watermarking in DWT Domain using Chaotic Mixtures", IEEE Latin America Transactions, Vol. 8, No. 3, June 2010, pp. $304-310$ 
[29] Alper Koz et. al., "Watermarking of Free - View Video", IEEE Transactions on Image Processing, Vol. 19, No. 7, July 2010, pp. $1785-1797$.

[30] Min - Jeong et. al., "Digital Cinema Watermarking for Estimating the Position of the Pirate", IEEE Transactions on Multimedia, Vol. 12, No. 7, November 2010, pp. 605 -621 .

[31]Liyun Wang et. al., "Real Time Compressed Domain Video Watermarking Resistance to Geometric Distortions", IEEE Multimedia in Forensics, Security and Intelligence, Computer society, January - March 2012 , pp. $70-79$.
[32] Andras Boho et. al., "End to End Security for Video Distribution", IEEE Signal Processing Magazine, March 2013, pp. $97-107$.

[33] Mehdi Fallahpour et. al., "Tampering Detection in Compressed Digital Video Using Watermarking" IEEE Transactions on Instrumentation and Measurement, Vol. 63, No. 5, May 2014, pp. 1057 - 1072.

[34] Md. Asikuzzaman et. al., "Imperceptible and Robust Blind Video Watermarking using Chrominance Embedding: A set of Approaches in the DT CWT Domain" IEEE Transactions on Information Forensics and Security, Vol. 9, No. 9, September 2014, pp. 1502 1517. 